\title{
Direct and indirect effects of amino acids on hepatic glucose metabolism in humans
}

\author{
M. Krebs ${ }^{1}$, A. Brehm ${ }^{1}$, M. Krssak ${ }^{1}$, C. Anderwald ${ }^{1}$, E. Bernroider ${ }^{1}$, P. Nowotny ${ }^{1}$, E. Roth ${ }^{2}$, V. Chandramouli ${ }^{3}$, \\ B. R. Landau ${ }^{3}$, W. Waldhäusl ${ }^{1}$, M. $\operatorname{Roden}^{1}$ \\ ${ }^{1}$ Division of Endocrinology and Metabolism, Department of Internal Medicine III, University of Vienna Medical School, Vienna, \\ Austria \\ ${ }^{2}$ Department of Surgery, University of Vienna Medical School, Vienna, Austria \\ ${ }^{3}$ Department of Medicine, Case Western Reserve University School of Medicine, Cleveland, Ohio, USA
}

\section{Abstract}

Aim/hypothesis. The study was designed to examine the contribution of direct (substrate-mediated) and indirect (hormone-mediated) effects of amino acids on hepatic glucose metabolism in healthy men.

Methods. The protocols were: (i) $\mathbf{C O N}+\mathbf{S}(n=7)$ : control conditions with somatostatin to inhibit endogenous hormone release resulting in fasting plasma concentrations of amino acids, insulin $(\sim 28 \mathrm{pmol} / \mathrm{l})$ and glucagon ( $65 \mathrm{ng} / \mathrm{l})$, (ii) $\mathbf{A A}+\mathbf{S}(n=7)$ : amino acid infusion-fasting insulinaemia-fasting glucagonaemia, (iii) $\mathbf{G L U C + S}(n=6)$ : fasting amino acids-fasting insulinaemia-hyperglucagonaemia $(\sim 99 \mathrm{ng} / \mathrm{l})$ and (iv) AA-S ( $n=5)$ : amino acid infusion without somatostatin resulting in amino acid-induced hyperinsulinaemia ( 61 pmol/l)-hyperglucagonaemia $(\sim 147 \mathrm{ng} / \mathrm{l})$. Net glycogenolysis was calculated from liver glycogen concentrations using ${ }^{13} \mathrm{C}$ nuclear magnetic resonance spectroscopy. Total gluconeogenesis (GNG) was calculated by subtracting net glycogenolysis from endogenous glucose production (EGP) which was measured with $\left[6,6-{ }^{2} \mathrm{H}_{2}\right]$ glucose. Net GNG was assessed with the ${ }^{2} \mathrm{H}_{2} \mathrm{O}$ method.

Results. During $\mathrm{AA}+\mathrm{S}$ and $\mathrm{GLUC}+\mathrm{S}$, plasma glucose increased by about $50 \%(p<0.01)$ due to a comparable rise in EGP. This was associated with a $53-\%(p<0.05)$ and a $65 \%$ increase $(p<0.01)$ of total and net GNG during $\mathrm{AA}+\mathrm{S}$, whereas net glycogenolysis rose by $70 \%(p<0.001)$ during GLUC+S. During AA-S, plasma glucose remained unchanged despite nearlydoubled $(p<0.01)$ total GNG.

Conclusion/interpretation. Conditions of postprandial amino acid elevation stimulate secretion of insulin and glucagon without affecting glycaemia despite markedly increased gluconeogenesis. Impaired insulin secretion unmasks the direct gluconeogenic effect of amino acids and increases plasma glucose. [Diabetologia (2003) 46:917-925]

Keywords Amino acids, endogenous glucose production, gluconeogenesis, glycogenolysis, liver glycogen, glucagon.
Received: 22 January 2003 / Revised: 28 February 2003

Published online: 18 June 2003

C) Springer-Verlag 2003

Corresponding author: Dr. M. Roden, Division of Endocrinology and Metabolism, Department of Internal Medicine III, University of Vienna Medical School, Währinger Gürtel 18-20, 1090 Vienna, Austria

E-mail: michael.roden@akh-wien.ac.at

Abbreviations: AA, amino acids; APE, atom percent excess; EGP, endogenous glucose production; GNG, gluconeogenesis; NMRS, nuclear magnetic resonance spectroscopy; S, somatostatin.
Development of Type 2 diabetes can be attributed to lifestyle in the vast majority of patients [1]. Dietary modification effectively delays or even prevents Type 2 diabetes in high-risk populations [2, 3]. This strongly supports the hypothesis that nutrient excess plays a central role in the development of this disease.

Nutrient excess not only comprises higher intake of fat, but also of proteins. Meat consumption has grown by about 33\% since 1960 in industrialized countries [4]. Increased plasma amino acid (AA) concentrations are detectable in insulin resistant states such as obesity $[5,6]$, and protein intake is associated with higher insulin requirements in Type 1 diabetic patients $[7,8]$. 
Thus, increased availability of AA could contribute to disturbance of carbohydrate metabolism [9]. In fact, we have shown that short-term AA infusion induces peripheral insulin resistance in healthy humans by inhibition of glucose transport/phosphorylation and subsequent reduction in glycogen synthesis [10]. Less information is available, however, concerning the effects of increased AA supply on hepatic glucose metabolism in humans.

Some data suggest that high protein intake could cause hyperglycaemia by stimulating endogenous glucose production (EGP) in the fasting state $[7,11,12$, $13,14]$. This increase would primarily depend on the altered secretion pattern of glucoregulatory hormones $[15,16,17]$ and subsequent changes in the portal insulin to glucagon ratio which regulates hepatic glucose metabolism [18]. In parallel, AA per se-by acting as substrates-could stimulate gluconeogenesis (GNG) [11], which would contribute to glucose production even in the early postprandial period $[19,20]$. The direct (substrate) effects of amino acids on hepatic glucose metabolism have been studied in several rodent models such as isolated rat livers [21] and canine models $[22,23]$. However, the respective roles of direct and indirect (hormone-mediated) effects of amino acids on hepatic glucose and glycogen metabolism have not yet been compared in vivo in humans.

This study was therefore designed to examine the direct and indirect effects of short term elevation of plasma AA on hepatic glucose metabolism by combining isotope dilution techniques including the ${ }^{2} \mathrm{H}_{2} \mathrm{O}$ method and in vivo ${ }^{13} \mathrm{C}$ nuclear magnetic resonance spectroscopy (NMRS) of the liver to simultaneously quantify EGP, GNG and glycogenolysis [19, 20].

\section{Subjects and Methods}

Volunteers. We included seven healthy male volunteers (age: $28 \pm 2$ yearsBMI: $22.9 \pm 0.9 \mathrm{~kg} / \mathrm{m}^{2}$ ) without family history of diabetes mellitus or dyslipidaemia in this study. They were neither glucose intolerant, suffering from conditions related to insulin resistance nor taking any medication. The protocols were approved by the local ethics board, and informed consent was obtained from all subjects after the nature and possible consequences of the procedures had been explained to them.

Study Protocols. All participants were instructed to ingest an isocaloric diet $(25 \mathrm{kcal} / \mathrm{kg}$ per day; carbohydrate/protein/fat: $55 \% / 15 \% / 30 \%$ ) for 3 days prior to the studies. After a $12-\mathrm{h}$ overnight fast, catheters were inserted at 6:00 a.m. (-240 min) into forearm veins of both arms for blood sampling and infusions. D-[6,6-2 H]glucose (98\% enrichment; Cambridge Isotope Laboratories, Andover, Mass., USA) was infused (bolus: $3 \mathrm{mg} / \mathrm{kg}$; continuous infusion: $0.03 \mathrm{mg} \mathrm{kg}^{-1} \mathrm{~min}^{-1}$ ) for measuring EGP from $-180 \mathrm{~min}$ to $360 \mathrm{~min}$.

Four experimental protocols were carried out. In three of them, pancreatic clamps were done to exclude indirect (hormone-mediated) AA effects resulting from AA-induced secretion of glucoregulatory hormones. Endogenous hormone secretion was inhibited by continuous infusion of somatostatin (S;
$0.11 \mu \mathrm{U} \mathrm{kg}^{-1} \mathrm{~min}^{-1}$; -5-360 min; UCB Pharma, Vienna, Austria). In addition, insulin (0.065 mU kg-1 $\mathrm{min}^{-1}$; Actrapid, Novo Nordisk, Bagsvaerd, Denmark), glucagon (0.9 ng kg-1 $\mathrm{min}^{-1}$; Novo Nordisk, Vienna, Austria) and growth hormone (2.0 ng kg-1 $\mathrm{min}^{-1}$; Genotropin, Upjohn and Pharmacia, Vienna, Austria) [24] were replaced from 0 to $360 \mathrm{~min}$ to provide for their fasting peripheral concentrations. A balanced AA mixture (0.2 $\mathrm{g} \mathrm{kg}^{-1} \mathrm{~h}^{-1}$; Aminoplasmal $10 \%$ without electrolytes, Braun, Melsungen, Germany) was infused (0-360 min) in order to create postprandial conditions of increased plasma AA concentrations as described previously [10]. During control studies, normal saline was infused at identical infusion rates. To compare direct (substrate-mediated) AA effects with that of glucagon, the glucagon infusion rates were doubled (1.8 ng $\mathrm{kg}^{-1} \mathrm{~min}^{-1}$ ) during one pancreatic clamp protocol without concomitant AA infusion.

These procedures resulted in the following protocols: (i) $\mathrm{CON}+\mathrm{S}(n=7)$ : control conditions with somatostatin (S) to inhibit pancreatic hormone release resulting in fasting (basal) concentrations of AA, insulin ( $28 \mathrm{pmol} / 1)$, glucagon ( $65 \mathrm{ng} / \mathrm{l})$ and growth hormone $(\sim 0.5 \mu \mathrm{g} / \mathrm{l})$, (ii) $\mathrm{AA}+\mathrm{S}(n=7)$ : AA infusion-fasting insulinaemia-fasting glucagonaemia-fasting plasma growth hormone, (iii) GLUC $+\mathrm{S}(n=6)$ : fasting AA-fasting insulinaemia-hyperglucagonaemia ( 99 ng/l)-fasting plasma growth hormone and (iv) AA-S $(n=5)$ : AA infusion without $\mathrm{S}$ resulting in hyperinsulinaemia ( 61 pmol/l)-hyperglucagonaemia $(\sim 147 \mathrm{ng} / \mathrm{l})$-slightly increased plasma growth hormone $(\sim 1.7 \mu \mathrm{g} / \mathrm{l})$.

To assess net GNG during protocols $\mathrm{AA}+\mathrm{S}$ and $\mathrm{CON}+\mathrm{S}$, the participants started at $-235 \mathrm{~min}$ to drink a total of $5 \mathrm{~g}$ of ${ }^{2} \mathrm{H}_{2} \mathrm{O}$ (99.9\% enrichment; Cambridge Isotope Laboratories, Andover, Mass., USA) per kilogram of body water divided into four equal doses spaced by 45-min intervals [19, 25]. Thereafter, they had free access to drinking water containing $0.5 \%$ of ${ }^{2} \mathrm{H}_{2} \mathrm{O}$ to maintain isotopic equilibrium in body water.

In vivo $13 C$ NMRS. During all protocols, liver glycogen concentrations were measured from -40 to $-10 \mathrm{~min}, 10$ to $40 \mathrm{~min}$, 120 to $150 \mathrm{~min}$, and from 300 to $360 \mathrm{~min}$ on a $3.0-\mathrm{T} / 80-\mathrm{cm}$ bore NMR spectrometer (Medspec, Bruker, Ettlingen, Germany). Localized ${ }^{13} \mathrm{C}$ resonance spectra were obtained with a $10 \mathrm{~cm}$ circular ${ }^{13} \mathrm{C} /{ }^{1} \mathrm{H}$ transmitter/receiver coil placed rigidly over the lateral aspect of the liver by applying a modified onedimensional inversion-based sequence [18, 20, 26]. Typically, one spectrum consists of 5000 scans and requires 15 min of signal averaging. The absolute liver glycogen concentration was quantified by comparing the $\mathrm{C} 1$ glycogen peak $(100.5 \mathrm{ppm})$ integral of liver spectra with that of a glycogen standard taken under identical conditions. Correction for loading of the coil and filling of the sensitive volume were done. Magnetic resonance imaging was carried out in a clinical 1.5-T scanner (Siemens, Erlangen, Germany) in order to determine liver volume (1.54 \pm 0.02 litre) [20].

Analytical procedures. During all protocols blood samples were drawn at identically timed intervals, immediately chilled, centrifuged and the supernatants were stored at $-80^{\circ} \mathrm{C}$.

Plasma metabolites and hormones. Plasma glucose was measured by the glucose oxidase method (Glucose analyzer II, Beckman Instr., Fullerton, Calif., USA). Individual plasma amino acids were measured by HPLC as described previously [27]. Plasma non-esterified fatty acids (NEFA) were assayed with a microfluorimetric method (Wako Chem USA, Richmond, Va., USA). In vitro lipolysis leading to artificially increased plasma NEFA concentrations was prevented by collecting blood into vials containing orlistat and rapid centrifuga- 
tion of the samples [28]. Plasma lactate and glycerol were measured enzymatically (Roche, Darmstadt, Germany). Plasma immunoreactive insulin, C-peptide, glucagon and growth hormone were measured by commercially available RIAs (insulin: Pharmacia, Uppsala Sweden; C-peptide: Cis, GifSur-Yvette, France; glucagon: Linco, St. Charles, Mo, USA; growth hormone: Sorin Biomedica, Saluggia, Italy). Plasma cortisol was determined following extraction and charcoaldextran separation by RIA [29]. Coefficients of variation for these assays were reported previously $[25,28,30]$.

Gas chromatography-mass spectrometry $(G C-M S)$. For calculation of net GNG, hydrogens bound to carbons 2 and 5 of blood glucose were isolated in formaldehyde and derivatized as hexamethylenetetramine, which was assayed by GC-MS [19].

For measurement of EGP, glucose was isolated, derivatized and tracer-to-tracee ratios (TTR) were determined by GC-MS on a Hewlett-Packard 5,890 gas chromatograph interfaced to a mass selective detector as reported previously [10].

Calculations and statistical evaluation. At baseline, steady state rates of EGP were calculated by dividing the tracer $([6,6-$ ${ }^{2} \mathrm{H}_{2}$ ]-glucose) infusion rate by the TTR [31]. During the clamp tests rates of glucose appearance $\left(R_{a}\right)$ and disappearance $\left(R_{d}\right)$ were calculated from TTR using Steele`s non-steady state equations [32] modified for the use of stable isotopes [33, 34]. Rates of net hepatic glycogenolysis $\left(\mu \mathrm{mol} \mathrm{kg} \mathrm{kg}^{-1} \mathrm{~min}^{-1}\right.$ ) were calculated from the best linear fit of the liver glycogen $(\mathrm{mmol} / \mathrm{l}$ liver) -time curves by the method of least squares and multiplying the slope of that line by the liver volume (in litres) divided by the body weight (in $\mathrm{kg}$ ) [20]. Rates of net glycogenolysis were calculated for the complete time period (0-360 min) as well as separately for the first (0-180 min) and the second (120-360 $\mathrm{min}$ ) half of the protocol. Linearity of these segments was confirmed by linear regression analysis $(p<0.05)$.

Glucose-6-phosphate synthesized from gluconeogenic precursors could be either converted to glucose which is released into the circulation or it could serve as a substrate for glycogen synthesis (glyconeogenesis). Thus, gluconeogenesis (GNG) is either defined as rate of formation of both (blood-) glucose and (liver-) glycogen via glucose-6-phosphate from gluconeogenic substrates (total GNG or glucose-6-phosphoneogenesis) or as rate of only (blood-) glucose synthesis from the same gluconeogenic precursors (net GNG) $[35,36]$. Rates of formation of glucose-6-phosphate, i.e. total GNG, are given as the difference between rates of EGP and net glycogenolysis (NMRS method) $[20,35]$. The fractional contribution of glucose synthesized from gluconeogenic precursors to EGP is estimated from the ratio of the ${ }^{2} \mathrm{H}$ enrichments bound at $\mathrm{C} 5$ to that at $\mathrm{C} 2$ of blood glucose after oral ${ }^{2} \mathrm{H}_{2} \mathrm{O}$ administration [19]. Rates of synthesis of glucose via glucose-6-phosphate, i.e. net GNG are calculated by multiplying this fraction by the rate of EGP $\left({ }^{2} \mathrm{H}_{2} \mathrm{O}\right.$ method) $[19,35]$.

Data are shown as means \pm SE. Differences between paired experimental protocols were analyzed by the paired two-tailed Student's $t$ test and between more than two groups by ANOVA and Dunnett's post hoc testing. Changes of sequential (timedependent) data within experiments were analyzed by ANOVA for repeated measurements. Differences were considered significant at $p$ values less than 0.05

\section{Results}

Amino acids. (AA) Fasting plasma AA concentrations were similar in all protocols (Fig. 1A, Table 1). Dur-
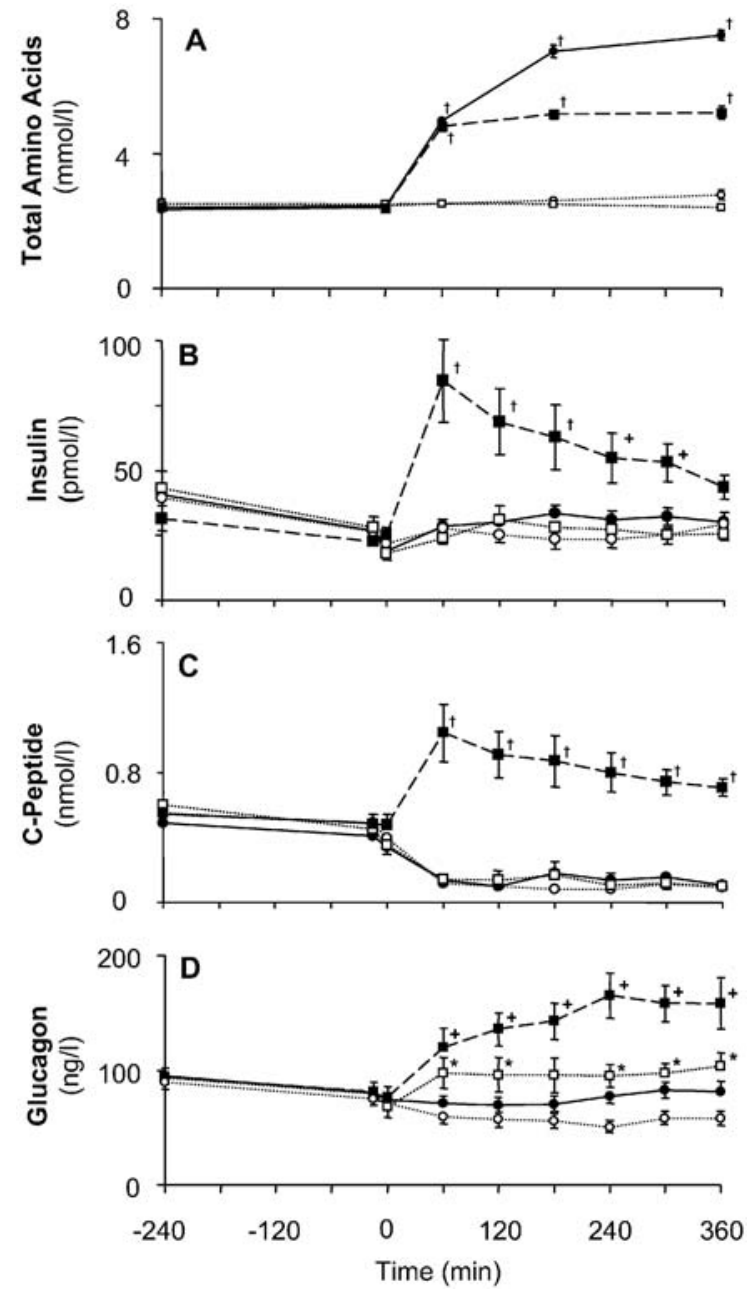

Fig. 1A-D. Plasma concentrations of total amino acids (A), insulin (B), C-peptide (C), and glucagon (D) during infusion of saline $(\mathrm{CON}+\mathrm{S}$, empty circles, $n=7)$ or amino acids $(\mathrm{AA}+\mathrm{S}$, full circles, $n=7)$ and selective glucagon elevation (GLUC+S, empty squares, $n=6$ ) together with somatostatin (pancreatic clamps) as well as infusion of amino acids without somatostatin (AA-S, full squares, $n=5)$. Data are given as means \pm SEM. $* p<0.05 ;+p<0.01, \dagger p<0.001$ vs $\mathrm{CON}+\mathrm{S}$

ing AA infusion with $(\mathrm{AA}+\mathrm{S})$ and without $(\mathrm{AA}-\mathrm{S})$ somatostatin, the total plasma AA concentrations increased by 3.2 fold $(p<0.01)$ and 2.1 fold $(p<0.01)$, respectively (Fig. 1A). Plasma concentrations of individual AA at baseline and during experimental conditions are presented in Table 1. Except for tyrosine all AA contributed to the rise in total plasma AA concentrations during AA infusion with somatostatin $(\mathrm{AA}+\mathrm{S})$. During AA-S, plasma AA rose to less extent than during AA+S (Fig. 1, Table 1). Serum electrolytes and osmolality were not affected by AA infusion (data not shown).

Hormones. Baseline plasma insulin and C-peptide concentrations were not different between the protocols (Fig. 1). During AA infusion without somatostatin (AA-S), plasma insulin and C-peptide concentra- 
Table 1. Plasma amino acid concentrations $(\mu \mathrm{mol} / \mathrm{l})$ at 0 and 360 min during infusion of saline $(\mathrm{CON}+\mathrm{S}, n=7)$ or amino acid $(\mathrm{AA}+\mathrm{S}, n=7)$ and selective glucagon elevation (GLUC+S, $n=6)$ together with somatostatin (pancreatic clamps) as well as infusion of amino acids without somatostatin (AA-S, $n=5$ ). Data are given as means \pm SEM

\begin{tabular}{|c|c|c|c|c|c|}
\hline Amino Acids & Time (min) & $\mathrm{CON}+\mathrm{S}$ & $\mathrm{AA}+\mathrm{S}$ & GLUC+S & AA-S \\
\hline \multirow{2}{*}{ Alanine } & 0 & $357 \pm 32$ & $305 \pm 21$ & $346 \pm 34$ & $342 \pm 51$ \\
\hline & 360 & $450 \pm 40$ & $1393 \pm 77^{* *}$ & $364 \pm 38$ & $849 \pm 21^{* *, * * * *}$ \\
\hline & 360 & $126 \pm 8$ & $523 \pm 26^{* *}$ & $94 \pm 6$ & $318 \pm 53^{* *}, * * * *$ \\
\hline \multirow{2}{*}{ Asparagine } & 0 & $46 \pm 1$ & $45 \pm 2$ & $48 \pm 1$ & $48 \pm 2$ \\
\hline & 360 & $53 \pm 2$ & $192 \pm 6^{* *}$ & $47 \pm 1$ & $118 \pm 5^{* *, * * * * *}$ \\
\hline \multirow[t]{2}{*}{ Glutamine } & 0 & $563 \pm 26$ & $558 \pm 33$ & $575 \pm 12$ & $602 \pm 16$ \\
\hline & 360 & $638 \pm 33$ & $892 \pm 38^{* *}$ & $600 \pm 18$ & $713 \pm 26^{* * * * *}$ \\
\hline \multirow[t]{2}{*}{ Glutamate } & 0 & $54 \pm 7$ & $56 \pm 4$ & $45 \pm 6$ & $33 \pm 6^{*}, * * *$ \\
\hline & 360 & $43 \pm 8$ & $113 \pm 11^{* *}$ & $26 \pm 3$ & $57 \pm 4^{* * * *}$ \\
\hline \multirow[t]{2}{*}{ Glycine } & 0 & $255 \pm 13$ & $246 \pm 16$ & $243 \pm 22$ & $234 \pm 12$ \\
\hline & 360 & $303 \pm 16$ & $980 \pm 41^{* *}$ & $228 \pm 17$ & $591 \pm 15^{* *, * * * *}$ \\
\hline \multirow[t]{2}{*}{ Leucine } & 0 & $130 \pm 5$ & $136 \pm 5$ & $133 \pm 7$ & $126 \pm 6$ \\
\hline & 360 & $189 \pm 45$ & $532 \pm 21^{* * *}$ & $138 \pm 5$ & $462 \pm 34^{* *}$ \\
\hline \multirow[t]{2}{*}{ Methionine } & 0 & $34 \pm 2$ & $34 \pm 2$ & $38 \pm 3$ & $34 \pm 2$ \\
\hline & 360 & $40 \pm 2$ & $267 \pm 13^{* *}$ & $38 \pm 3$ & $194 \pm 15^{\text {******* }}$ \\
\hline \multirow[t]{2}{*}{ Phenylalanine } & 0 & $53 \pm 2$ & $52 \pm 2$ & $55 \pm 3$ & $50 \pm 2$ \\
\hline & 360 & $55 \pm 3$ & $210 \pm 5^{* *}$ & $53 \pm 2$ & $174 \pm 6^{* *, * * * * *}$ \\
\hline \multirow[t]{2}{*}{ Serine } & 0 & $125 \pm 7$ & $133 \pm 9$ & $116 \pm 8$ & $113 \pm 8$ \\
\hline & 360 & $140 \pm 9$ & $342 \pm 20^{* *}$ & $105 \pm 4$ & $184 \pm 18^{* * * * *}$ \\
\hline \multirow[t]{2}{*}{ Taurine } & 0 & $51 \pm 9$ & $42 \pm 2$ & $45 \pm 3$ & $41 \pm 1$ \\
\hline & 360 & $42 \pm 2$ & $67 \pm 4^{* *}$ & $40 \pm 3$ & $47 \pm 3^{* * * *}$ \\
\hline \multirow[t]{2}{*}{ Threonine } & 0 & $129 \pm 6$ & $128 \pm 9$ & $120 \pm 6$ & $116 \pm 4$ \\
\hline & 360 & $146 \pm 7$ & $468 \pm 20^{* * *}$ & $114 \pm 6$ & $271 \pm 13^{* *}, * * * *$ \\
\hline
\end{tabular}

$* p<0.05,{ }^{* *} p<0.01$, vs. $\mathrm{CON}+\mathrm{S} ;{ }^{* * *} p<0.05,{ }^{* * * *} p<0.01$ vs $\mathrm{AA}+\mathrm{S}$

tions rapidly increased ( $p<0.001$ vs baseline; Fig. 1B, Fig. 1C). During pancreatic clamp tests $(\mathrm{CON}+\mathrm{S}$, $\mathrm{AA}+\mathrm{S}, \mathrm{GLUC}+\mathrm{S}$ ), plasma insulin (Fig. 1B) remained at baseline and plasma C-peptide concentrations (Fig. 1C) were equally suppressed.

Plasma glucagon concentrations were similar at baseline and remained close to baseline during $\mathrm{CON}+\mathrm{S}$ and $\mathrm{AA}+\mathrm{S}$. During AA infusion without somatostatin (AA-S) and during doubled rates of glucagon infusion $(\mathrm{GLUC}+\mathrm{S})$, plasma glucagon increased by about $162 \% \quad(p<0.01)$ and about $74 \% \quad(p<0.05)$ within $60 \mathrm{~min}$ and remained higher until $360 \mathrm{~min}$ compared to $\mathrm{CON}+\mathrm{S}$ and baseline (Fig. 1D).

At baseline, plasma growth hormone concentration varied without statistical significance $(-240 \mathrm{~min}$ : $\mathrm{CON}+\mathrm{S}: \quad 0.80 \pm 0.56, \mathrm{AA}+\mathrm{S}: 0.25 \pm 0.08, \mathrm{GLUC}+\mathrm{S}$ : $0.17 \pm 0.03$, AA-S: $0.19 \pm 0.04 \mu \mathrm{g} / \mathrm{l}$; N.S.) because of its spontaneous pulsatile secretion pattern [37]. During the pancreatic clamp tests $(\mathrm{CON}+\mathrm{S}, \mathrm{AA}+\mathrm{S}, \mathrm{GLUC}+\mathrm{S})$, plasma growth hormone concentrations were comparable between the protocols. In the absence of somatostatin (AA-S), mean growth hormone secretion peaked at $180 \mathrm{~min}$, but again was not statistically different compared with the other protocols $(180 \mathrm{~min}: \mathrm{CON}+\mathrm{S}$ : $0.52 \pm 0.18, \mathrm{AA}+\mathrm{S}: 0.49 \pm 0.21, \mathrm{GLUC}+\mathrm{S}: 0.14 \pm 0.02$, AA-S: $3.86 \pm 2.37 \mu \mathrm{g} / \mathrm{l}$; N.S.).

Plasma cortisol concentrations were comparable between all protocols $(0 \mathrm{~min}: \mathrm{CON}+\mathrm{S}: 350 \pm 46, \mathrm{AA}+\mathrm{S}$ : 343 \pm 40 , GLUC+S: $342 \pm 40$, AA-S: $328 \pm 58 \mathrm{nmol} / \mathrm{l}$; 360 min: $\mathrm{CON}+\mathrm{S}: 214 \pm 32, \mathrm{AA}+\mathrm{S}: 281 \pm 34$, GLUC+S: $198 \pm 26$ AA-S: $191 \pm 10 \mathrm{nmol} / \mathrm{l})$.

Metabolites. Plasma NEFA concentrations were similar in all protocols $(-240 \mathrm{~min} ; \mathrm{CON}+\mathrm{S}: 0.49 \pm 0.13$, $\mathrm{AA}+\mathrm{S}: \quad 0.58 \pm 0.06, \quad \mathrm{GLUC}+\mathrm{S}: \quad 0.46 \pm 0.12$, AA-S: $0.48 \pm 0.05 \mathrm{mmol} / \mathrm{l} ; 360 \mathrm{~min}: \mathrm{CON}+\mathrm{S}$ : $0.24 \pm 0.04$, 


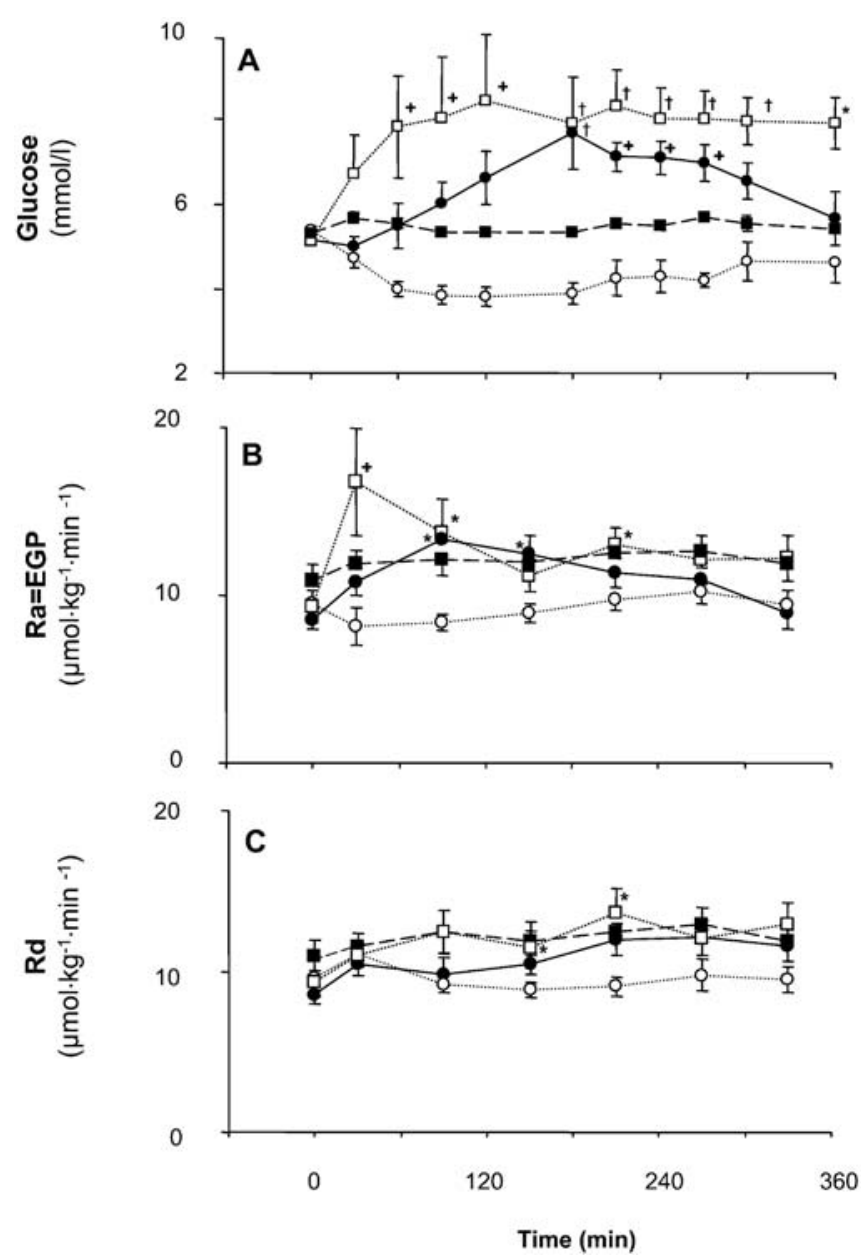

Fig. 2A-C. Plasma concentrations of glucose (A), rates of glucose appearance (endogenous glucose production) (B) and rates of glucose disappearance $(\mathbf{C})$ during infusion of saline $(\mathrm{CON}+\mathrm{S}$, empty circles, $n=7)$ or amino acids $(\mathrm{AA}+\mathrm{S}$, full circles, $n=7)$ and selective glucagon elevation (GLUC+S, empty squares, $n=6)$ together with somatostatin (pancreatic clamps) as well as infusion of amino acids without somatostatin (AA-S, full squares, $n=5)$. Data are given as means \pm SEM. ${ }^{*} p<0.05$; $+p<0.01, \dagger p<0.001$ vs. $\mathrm{CON}+\mathrm{S}$

AA+S: $\quad 0.15 \pm 0.04, \quad$ GLUC + S: $0.12 \pm 0.03, \quad$ AA-S : $0.22 \pm 0.03 \mathrm{mmol} / \mathrm{l})$. Plasma glycerol and lactate concentrations neither changed from baseline values nor differed between the four protocols (individual data not shown).

Glucose metabolism. Fasting plasma glucose concentrations were comparable between the protocols (Fig. 2A). During AA-S, plasma glucose remained at baseline and did not change throughout the study. When AA-mediated hormone secretion was inhibited by somatostatin, plasma glucose increased by about $50 \%(p<0.05)$ during $\mathrm{AA}$ infusion $(\mathrm{AA}+\mathrm{S})$ between $180 \mathrm{~min}$ and $270 \mathrm{~min}$ (Fig. 2A). The selective rise in plasma glucagon concentrations during GLUC+S also resulted in an increase in plasma glucose $(p<0.05$ vs baseline from 60 to $360 \mathrm{~min}$ ). During $\mathrm{CON}+\mathrm{S}$, plasma

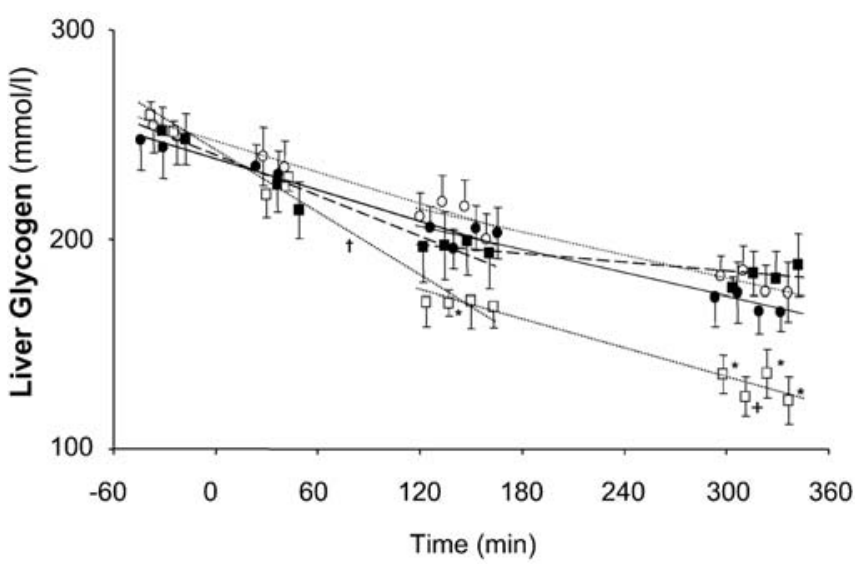

Fig. 3. Time course of liver glycogen concentrations and rates of net glycogenolysis during infusion of saline $(\mathrm{CON}+\mathrm{S}$, empty circles, $n=7)$ or amino acids (AA+S, full circles, $n=7)$ and selective glucagon elevation (GLUC+S, empty squares, $n=6$ ) together with somatostatin (pancreatic clamps) as well as infusion of amino acids without somatostatin (AA-S, full squares, $n=5$ ). Data are given as means \pm SEM. Glycogen concentrations: $* p<0.05 ;+p<0.01$ vs $\mathrm{CON}+\mathrm{S}$. Rates of net glycogenolysis: $\dagger p<0.001$ vs $\mathrm{CON}+\mathrm{S}$

glucose slightly decreased $(p<0.01)$ from baseline values between 60 and $270 \mathrm{~min}$.

EGP was comparable between all protocols at zero time $(\mathrm{CON}+\mathrm{S}: 9.6 \pm 0.7, \mathrm{AA}+\mathrm{S}:$ 8.6 $\pm 0.6, \mathrm{GLUC}+\mathrm{S}$ : 9.4 \pm 0.9 , AA-S: $\left.10.6 \pm 1.0 \mu \mathrm{mol} \mathrm{kg} \mathrm{kg}^{-1} \mathrm{~min}^{-1}\right)$. During AA-S, EGP only slightly increased $(p<0.05)$ above baseline between $60 \mathrm{~min}$ and $300 \mathrm{~min}$. In contrast, EGP rose by about $33 \%$ and about $42 \%$ during $\mathrm{AA}+\mathrm{S}$ and GLUC+S, respectively and was higher $(p<0.05)$ than under fasting and control conditions $(\mathrm{CON}+\mathrm{S}$; Fig. 2B). This rise in EGP preceded the increase in plasma glucose concentrations (Fig. 2A). As expected, EGP remained close to baseline during $\mathrm{CON}+\mathrm{S}$. Subsequent to the rise in plasma glucose, Rd gradually increased by about $35 \%$ and about $37 \%$ during $\mathrm{AA}+\mathrm{S}$ $(p<0.05$ from 180 to $300 \mathrm{~min})$ and GLUC+S $(p<0.01$ from 60 to $360 \mathrm{~min}$ ), respectively. Rd was also slightly higher during AA-S compared to baseline $(p<0.05)$ from 180 to $300 \mathrm{~min}$ (Fig. 2C). Under control conditions $(\mathrm{CON}+\mathrm{S}) \mathrm{Rd}$ did not change from baseline (Fig. 2C).

Hepatic glycogen metabolism. Baseline liver glycogen concentrations were similar in all protocols $(\mathrm{CON}+\mathrm{S}$ : $254 \pm 13$, AA+S: $247 \pm 15$, GLUC+S: $259 \pm 7$, AA-S: $251 \pm 11 \mathrm{mmol} / \mathrm{l}$ liver) (Fig. 3). AA infusion with $(\mathrm{AA}+\mathrm{S})$ or without somatostatin (AA-S) neither affected the glycogen concentration-time course nor net glycogenolysis. Only by doubling the glucagon infusion rate $(\mathrm{GLUC}+\mathrm{S})$, net glycogenolysis was about two-fold higher than during $\mathrm{CON}+\mathrm{S}$ in the first half of the study $\left(10.4 \pm 1.3\right.$ vs $5.0 \pm 0.4 \mu \mathrm{mol} \mathrm{kg} \mathrm{kg}^{-1} \mathrm{~min}^{-1}$, $p<0.001)$. Net glycogenolysis was also higher when calculated for the complete time period of $360 \mathrm{~min}$ 
Table 2. Rates of net glycogenolysis, total GNG calculated by subtracting rates of net glycogenolysis (0-360 min) from mean rates of EGP (0-360 min) (NMRS method) and rates of net GNG calculated from mean rates of EGP (0-360 $\mathrm{min})$ and mean ${ }^{2} \mathrm{H}$ enrichments in carbons 2 and 5 of blood glucose drawn at 180 and $360 \mathrm{~min}\left({ }^{2} \mathrm{H}_{2} \mathrm{O}\right.$ method) during the following protocols: infusion of saline $(\mathrm{CON}+\mathrm{S}, n=7)$ or amino acids $(\mathrm{AA}+\mathrm{S}, n=7)$ and selective glucagon elevation (GLUC+S, $n=6$ ) together with somatostatin (pancreatic clamps) as well as infusion of amino acids without somatostatin (AA-S, $n=5$ ). Data are given as means \pm SEM

\begin{tabular}{|c|c|c|c|}
\hline \multirow[t]{2}{*}{ Protocol } & \multicolumn{2}{|l|}{ NMRS method } & \multirow{2}{*}{$\begin{array}{l}{ }^{2} \mathrm{H}_{2} \mathrm{O} \text { method } \\
\text { Rates of net } \mathrm{GNG} \\
\left(\mu \mathrm{mol} \mathrm{kg}-1 \mathrm{~min}^{-1}\right)\end{array}$} \\
\hline & $\begin{array}{l}\text { Rates of net glycogenolysis } \\
\left(\mu \mathrm{mol} \mathrm{kg} \mathrm{min}^{-1}\right)\end{array}$ & $\begin{array}{l}\text { Rates of total GNG } \\
\left(\mu \mathrm{mol} \mathrm{kg} \mathrm{kgin}^{-1}\right)\end{array}$ & \\
\hline $\mathrm{CON}+\mathrm{S}$ & $4.3 \pm 0.3$ & $4.5 \pm 0.5$ & $4.0 \pm 0.3$ \\
\hline $\mathrm{AA}+\mathrm{S}$ & $4.4 \pm 0.2$ & $6.9 \pm 0.5 *$ & $6.6 \pm 0.3^{* *}$ \\
\hline GLUC+S & $7.3 \pm 0.5^{* * *}$ & $5.9 \pm 0.9$ & n.d. \\
\hline
\end{tabular}

$* p<0.05 ; * * p<0.01, * * * p<0.001$ vs CON+S; n.d. not determined

(Table 2). Furthermore, net glycogenolysis was higher in the first $(0-180 \mathrm{~min}$; GLUC+S: $10.4 \pm 1.3$, AA-S: $6.1 \pm 0.7 \mu \mathrm{mol} \mathrm{kg}-1 \mathrm{~min}^{-1}$ ) than in the second half of the GLUC+S and AA-S protocols (120-360 min; GLUC+S: $4.7 \pm 0.6$, AA-S: $1.8 \pm 0.7 \mu \mathrm{mol} \mathrm{kg}{ }^{-1} \mathrm{~min}^{-1}$; $p<0.05$ vs. $0-180 \mathrm{~min})$. During control conditions $(\mathrm{CON}+\mathrm{S})$ and $\mathrm{AA}+\mathrm{S}$, net glycogenolysis was similar in both periods of these protocols $(0-180 \mathrm{~min}$; $\mathrm{CON}+\mathrm{S}: 5.0 \pm 0.4, \mathrm{AA}+\mathrm{S}: 4.9 \pm 0.7 \mu \mathrm{mol} \mathrm{kg} \mathrm{km}^{-1} \mathrm{~min}^{-1}$ and 120-360 min; $\mathrm{CON}+\mathrm{S}: 3.7 \pm 0.6, \mathrm{AA}+\mathrm{S}: 4.0 \pm$ $0.5 \mu \mathrm{mol} \mathrm{kg} \mathrm{kg}^{-1} \mathrm{~min}^{-1}$, N.S.).

Net and total gluconeogenesis. At baseline, rates of net GNG as obtained by the ${ }^{2} \mathrm{H}_{2} \mathrm{O}$ method were comparable between $\mathrm{AA}+\mathrm{S}$ and $\mathrm{CON}+\mathrm{S}(4.7 \pm 0.3$ and $4.2 \pm 0.3 \mu \mathrm{mol}$ $\left.\mathrm{kg}^{-1} \mathrm{~min}^{-1}\right)$. During AA infusion $(\mathrm{AA}+\mathrm{S})$, net GNG increased by about $40 \%(p<0.01)$ over baseline and was about $65 \%$ greater $(p<0.01)$ than in $\mathrm{CON}+\mathrm{S}$, but remained at baseline values during $\mathrm{CON}+\mathrm{S}$. Rates of total GNG as obtained by NMRS were not different from rates of net GNG (Table 2).

The respective contribution of total GNG and net glycogenolysis to EGP was analyzed separately for the first $(0-180 \mathrm{~min})$ and the second half (120-360 min) of all protocols (Fig. 4). During $\mathrm{AA}+\mathrm{S}$, EGP increased by about $50 \% \quad(p<0.05$ vs $\mathrm{CON}+\mathrm{S}$ ) which was associated with an about $131 \%$ rise of total GNG in the first $180 \mathrm{~min}(p<0.05$ vs respective time period during $\mathrm{CON}+\mathrm{S}$ ).

During GLUC+S, EGP increased by about $71 \%$ compared with $\mathrm{CON}+\mathrm{S}(p<0.01)$, which was accompanied by doubling the rates of net glycogenolysis in the first $180 \mathrm{~min}$. In contrast, the rise in EGP by about 33\% $(p<0.05)$ during the second half of GLUC+S was associated with slightly but not significantly augmented total GNG. During AA infusion without somatostatin (AA-S), EGP was about $48 \%(p<0.05)$ and about $34 \%$ $(p<0.05)$ higher compared to $\mathrm{CON}+\mathrm{S}$ in the first and second half of the protocol. Elevation of EGP was almost exclusively accounted for by an increased $(\sim 96 \%$, $p<0.01)$ total GNG in the second half of the study.

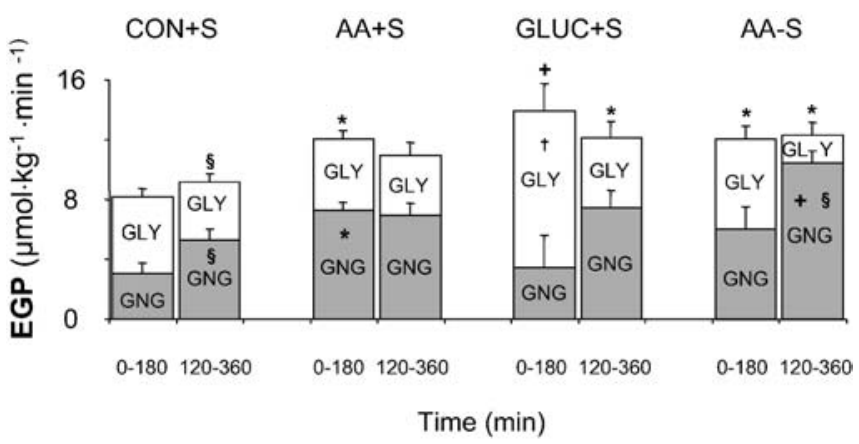

Fig. 4. Contributions of total gluconeogenesis (GNG) and net glycogenolysis (GLY; NMR method) to tracer determined rates of endogenous glucose production (EGP) in the first (0-180 $\mathrm{min})$ and second (120-360 $\mathrm{min})$ halves of the following studies; Saline $(\mathrm{CON}+\mathrm{S}, n=7)$ or amino acid $(\mathrm{AA}+\mathrm{S}, n=7)$ infusion and selective glucagon elevation (GLUC+S, $n=6)$ together with somatostatin (pancreatic clamps) as well as infusion of amino acids without somatostatin (AA-S, $n=5$ ). Data are given as means \pm SEM. $* p<0.05 ;+p<0.01, \dagger p<0.001$ vs corresponding time frame during $\mathrm{CON}+\mathrm{S}$. \& $p<0.05$ vs. first half of the respective study

\section{Discussion}

This study shows that in the presence of fasting peripheral insulin and glucagon concentrations, hyperglycaemia in response to a short term rise in plasma AA to postprandial portal levels [38] is secondary to increased GNG and EGP. This direct (substrateinduced) effect can be clearly separated from the indirect (hormone-meditated) AA action which depends on an increase in the glucagon-to-insulin ratio and does not affect plasma glucose concentration.

Direct AA effects. In protocol $\mathrm{AA}+\mathrm{S}$, the rise in plasma glucose in response to the plasma AA elevation was observed under conditions of fasting peripheral concentrations of glucoregulatory hormones. Thus, it has to be attributed to a direct metabolic AA action which could be: (i) reduced peripheral glucose disposal (Rd) and/or (ii) increased EGP due to augmented 
glycogenolysis or GNG. We have recently shown that a comparable AA infusion decreases insulin-stimulated peripheral glucose disposal by about $25 \%$ primarily by interfering with skeletal muscle glucose transport/ phosphorylation in healthy humans [10]. Our study indicates that under conditions of fasting insulinaemia plasma AA elevation does not decrease $\mathrm{Rd}$, which rather tended to increase during hyperglycaemia independent of insulin and is therefore most likely due to the mass action of glucose [39, 40, 41]. Consequently, insulin-dependent glucose uptake into skeletal muscle did not play a major role under the experimental conditions of this study [42]. The fall of plasma glucose towards baseline values during the second period of the $\mathrm{AA}+\mathrm{S}$ protocol can be explained by the decrease of EGP which likely resulted from inhibition by hyperglycaemia [43] during the preceding $180 \mathrm{~min}$. In addition, glucose-stimulated glucose disposal accounted for the gradually increased $\mathrm{Rd}[39,40,41]$, which in turn could have caused the fall in plasma glucose concentrations during the second period of $\mathrm{AA}+\mathrm{S}$.

On the other hand, EGP markedly increased in the $\mathrm{AA}+\mathrm{S}$ protocol, although net glycogenolysis was comparable to that of control studies $(\mathrm{CON}+\mathrm{S})$. Thus, the augmented total and net GNG during the first 180 min primarily accounted for the observed rise in EGP. Moreover, combining ${ }^{13} \mathrm{C}$ NMRS with the ${ }^{2} \mathrm{H}_{2} \mathrm{O}$ method made it possible to assess simultaneous glycogen synthesis during active glycogen breakdown from knowledge of rates of EGP, total and net GNG [35]. Total and net GNG were not different suggesting that under the conditions of the study there was little if any glycogen cycling [35].

It is of note that AA, mainly alanine and glutamine, derived from exogenous or endogenous proteins are the major source of de novo glucose formation, because lactate is derived from glucose and GNG from glycerol becomes quantitatively important only in the presence of accelerated lipolysis [11]. In the present study an AA mixture containing all gluconeogenic AA was infused so that one cannot discriminate between the impact of individual AA or a certain combination of AA on the obtained results.

These results are in line with studies in dogs that have shown that infusion of AA, which were disposed by about $90 \%$ into the splanchnic tissues, inducing a rise in hepatic glucose production [44]. Thus, direct effects of AA on GNG are likely explained by increased supply of gluconeogenic substrates. AA could also substitute as an oxidative fuel for other substrates and shunt them into the gluconeogenic pathway. Alternatively AA might induce genes of key gluconeogenic enzymes [45] similar to the action of glucagon [46].

Indirect AA effects. Amino acids are well-known to simultaneously stimulate endogenous insulin and glucagon release $[15,16,17]$. Thus, the indirect (hormone- mediated) AA effects need to be considered in addition to their direct metabolic effects. One previous report suggested that AA infusion could increase EGP by stimulating GNG in humans [47]. However, plasma glucagon concentrations were not controlled and remained consistently high during AA delivery in that study $[47,48]$ so it cannot be ruled out that stimulation of GNG by glucagon was responsible or at least contributed to the metabolic AA effect. Our study also aimed to compare the direct AA action on EGP and GNG with that of a selective rise in plasma glucagon concentrations (GLUC+S). We attempted to induce a similar increase in plasma glucose concentrations and rates of EGP during GLUC+S compared with the protocol testing direct AA effects $(\mathrm{AA}+\mathrm{S})$. This was achieved by doubling the glucagon infusion rate $(\mathrm{GLUC}+\mathrm{S})$ and this resulted in a rapid, but evanescent [49] rise in EGP secondary to stimulated glycogenolysis [42]. The observed effect is in contrast to the direct AA action leading to prompt stimulation of GNG. During glucagon administration, augmented net glycogenolysis explained $74 \%$ of EGP in the first half, but only $39 \%$ of EGP in the second half of the study indicating that only prolonged stimulation by glucagon increases GNG. These results confirm data obtained in dogs showing glucagon stimulated glycogenolysis first and thereafter GNG which progressively increased over time [50].

To test the combined (direct and indirect) effects of AA on hepatic glucose metabolism, AA were also infused in the absence of somatostatin (AA-S). This procedure did not affect plasma glucose concentrations despite elevated EGP. In line with previous observations [15, 16, 17] AA simultaneously-stimulated endogenous insulin and glucagon release. Consistent with arginine-induced growth hormone secretion [51], plasma growth hormone concentrations also tended to be higher under these conditions. Both direct (substrate) and indirect (glucagon mediated) AA effects therefore contributed to the observed increase in EGP and net glycogenolysis. The latter was more pronounced during the first half of this protocol than during control conditions. This effect is probably due to stimulation of glucagon secretion. However, in the second half of the experiment a marked increase in GNG was observed which primarily related to increased AA (substrate) supply and glucagon-mediated upregulation of gluconeogenic enzymes [11, 52]. Furthermore, insulin- and glucagon-stimulated (hepatic) AA uptake $[11,53]$ could have not only contributed to the up-regulation of GNG but also to the lower plasma AA concentrations during AA-S compared to AA+S. However, the rise in EGP was obviously counterbalanced by an insulin-stimulated increase in Rd, which thereby served to maintain fasting plasma glucose concentrations.

The effect of increased AA supply on hepatic glycogen metabolism has been controversial. In rats, high 
dietary protein intake did not affect rates of hepatic glycogen synthesis during intraduodenal glucose infusion [13], whereas a protein meal led to glycogen depletion, secondary to increased glucagon concentrations [54]. When glucagon was kept at its basal levels during pancreatic clamps, intraportal gluconeogenic AA decreased [23], but peripheral AA delivery increased [22] net hepatic glucose uptake and glycogen synthesis in dogs. This indicates that intraportal AA delivery could generate a signal that suppresses hepatic glucose uptake. In our study carried out in humans, rates of net glycogenolysis were identical suggesting that AA do not directly stimulate glycogen synthesis.

It is of note that high protein intake is associated with insulin resistance and glucose intolerance in humans [12, 14] and rodents [13]. Moreover, in insulindependent diabetes splanchnic AA uptake is elevated [55] and protein ingestion increases plasma glucose and insulin requirements in these patients $[7,8]$. The plasma AA concentrations observed in this study are within the range of those reached in the portal vein after ingestion of a protein meal [38]. Furthermore, the time course of plasma AA during the AA infusion is comparable to the pattern of plasma AA concentrations after ingestion of beef protein [56]. This indicates that changes in plasma AA concentrations within the physiologic range are sufficient to affect hepatic glucose metabolism. However, it cannot be excluded that incretins released from the gut in response to oral protein intake [57] or the portal route of AA supply to the liver [22] modulate the described effects of parenteral AA infusion under physiological conditions.

In conclusion, conditions creating postprandial amino acid elevation stimulate secretion of insulin and glucagon, but do not affect glycaemia despite markedly increased gluconeogenesis. However, impaired insulin secretion unmasks this direct gluconeogenic effect of amino acids and results in overt hyperglycaemia.

Acknowledgements. This study was supported by grants from the Austrian Science Foundation (FWF; 13213-MOB, P13722MED, P15656), the European Foundation for the Study of Diabetes (EFSD, Novo-Nordisk Type 2 Program Focussed Research grant, 2002) and the Herzfelder'sche Familienstiftung (Austria, 2003) to MR, by the National Institutes of Health (DK-14507) to BRL as well as by Novo-Nordisk to WW. We gratefully acknowledge the excellent cooperation with F. Garo, A. Hofer, H. Lentner, the Endocrine Laboratory and Professor E. Moser (Institute of Medical Physics, University of Vienna Medical School, Austria).

\section{References}

1. Hu FB, Manson JE, Stampfer MJ et al. (2001) Diet, lifestyle and the risk of type 2 diabetes mellitus in women. N Engl J Med:790-797

2. Diabetes Prevention Program Research Group (2002) Reduction in the incidence of type 2 diabetes with lifestyle intervention or metformin. N Engl J Med 346:393-403
3. Tuomilehto J, Lindström J, Eriksson JG et al. (2001) Prevention of type 2 diabetes mellitus by changes in lifestyle among subjects with impaired glucose tolerance. N Engl J Med 344:1343-1350

4. Karg G (2000) Nutrition in Germany. In: German Nutrition Society (eds) German nutrition report. Henrich, Frankfurt, pp 17-77

5. Felig P, Wahren J, Hendler R, Brundin T (1974) Splanchnic glucose and amino acid metabolism in obesity. J Clin Invest 53:582-590

6. Felig P, Marliss E, Cahill G (1969) Plasma amino acid levels and insulin secretion in obesity. $\mathrm{N}$ Engl $\mathrm{J}$ Med 281:811-816

7. Lariviere F, Chiasson J, Taveroff A, Hoffer L (1994) Effects of dietary protein restriction on glucose and insulin metabolism in normal and diabetic humans. Metabolism 43:462-467

8. Peters AL, Davidson MB (1993) Protein and fat effects on glucose responses and insulin requirements in subjects with insulin-dependent diabetes mellitus. Am J Clin Nutr 58:555-560

9. Patti M (1999) Nutrient modulation of insulin action. Ann NY Acad Sci (892):187-203

10. Krebs M, Krssak M, Bernroider E et al. (2002) Mechanism of amino acid-induced skeletal muscle insulin resistance in humans. Diabetes 51:599-605

11. Felig P (1975) Amino acid metabolism in man. Annu Rev Biochem 44:933-955

12. Linn T, Grönemeyer D, Aygen S, Scholz N, Busch M, Bretzel R (2000) Effect of long-term dietary protein intake on glucose metabolism in humans. Diabetologia 43:12571265

13. Rossetti L, Rothman D, DeFronzo R, Shulman G (1989) Effect of dietary protein on in vivo insulin and liver glycogen repletion. Am J Physiol 257:E212-E219

14. Linn T, Geyer R, Prassek S, Laube H (1996) Effect of dietary protein intake on insulin secretion and glucose metabolism in insulin-dependent diabetes mellitus. J Clin Endocrinol Metab 81:3938-3943

15. Bratusch-Marrian P, Björkmann O, Hagenfeldt L, Waldhäusl W, Wahren J (1979) Influence of arginine on splanchnic glucose metabolism in man. Diabetes 28:126-131

16. Floyd J, Fayans S, Conn J, Knopf R, Rull J (1966) Stimulation of insulin secretion by amino acids. J Clin Invest 45:1487-1502

17. Ohneda A, Parada E, Eisentraut A, Unger R (1968) Characterization of response of circulating glucagon to intraduodenal and intravenous administration of amino acids. J Clin Invest 47:2305-2322

18. Roden M, Pershegin G, Petersen K et al. (1996) The role of insulin and glucagon in the regulation of hepatic glycogen turnover in humans. J Clin Invest 97:642-648

19. Landau BR, Wahren J, Chandramouli V, Schumann WC, Eckberg K, Kalhan SC (1996) Contributions of gluconeogenesis to glucose production in the fasted state. J Clin Invest 98:378-385

20. Rothman D, Magnusson I, Katz L, Shulman R, Shulman G (1991) Quantitation of hepatic glycogenolysis and gluconeogenesis in fasting humans with C-13 NMR. Science 254:573-576

21. Ross BD, Hems R, Krebs HA (1967) The rate of gluconeogenesis from various precursors in the perfused rat liver. Biochem J 102:942-951

22. Moore MC, Hsieh P, FLakoll PJ, Neal DW, Cherrington AD (1999) Differential effect of amino acid infusion route on net hepatic glucose uptake in the dog. Am J Physiol: E295-E302 
23. Moore MC, FLakoll PJ, Hsieh P et al. (1998) Hepatic disposition during concomitant portal glucose and amino acid infusion in the dog. Am J Physiol:E893-E902

24. Nielsen M, Dinneen S, Basu R, Alzaid A, Rizza R (1998) Failure of nocturnal changes in growth hormone to alter carbohydrate tolerance the following morning. Diabetologia 41:1064-1072

25. Roden M, Stingl H, Chandramouli V et al. (2000) Effects of free fatty acids elevation on postabsorptive endogenous glucose production and gluconeogenesis in humans. Diabetes 49:701-707

26. Bischof MG, Krssak M, Krebs M et al. (2001) Effects of short-term improvement of insulin treatment and glycemia on hepatic glycogen metabolism in type 1 diabetes mellitus. Diabetes 50:392-398

27. Spittler A, Sautner T, Gornikiewicz A et al. (2001) Postoperative glycyl-glutamine infusion reduces immunosuppression: partial prevention of the surgery induced decrease in HLA-DR expression on monocytes. Clin Nutr 20:37-42

28. Krebs M, Stingl H, Nowotny P et al. (2000) Prevention of in vitro lipolysis by tetrahdrolipstatin. Clin Chem 46:950-954

29. Waldhäusl W, Herkner K, Nowotny P, Bratusch-Marrain P (1978) Combined 17- and 18-hydroxylase deficiency associated with complete male pseudohermaphroditism and hypoaldosteronism. J Clin Endocrinol Metab 46:236

30. Stingl H, Krssak M, Krebs M et al. (2000) Lipid-dependent control of hepatic glycogen stores in healthy man. Diabetologia 44:48-54

31. Radziuk J, Pye S (2002) Quantitation of basal endogenous glucose production in type II diabetes. Diabetologia 45:1053-1084

32. Hother-Nielsen O, Vaag A, Skott P, Beck-Nielsen H (1993) Effect of hyperglycemia per se on glucose turnover rates in patients with insulin dependent diabetes. Metabolism 42:86-93

33. Cobelli C, Toffolo G, Foster DM (1992) Tracer-to-tracee ratio for analysis of stable isotope tracer data: link with radioactive kinetic formalism. Am J Physiol 262:E968-E975

34. Gastaldelli A, Coggan AR, Wolfe RR (1999) Assessment of methods for improving tracer estimation of non-steadystate rate of appearance. J Appl Physiol 87:1813-1822

35. Landau BR (2001) Methods for measuring glycogen cycling. Am J Physiol 281:E413-E419

36. Krebs HA (1963) Renal gluconeogenesis. Adv Enzyme Regul 1:385-400

37. Thorner MO, Vance ML, Laws ER, Horvath E, Kovacs K (1998) The anterior pituitary. In: Wilson JD, Foster DW, Kronenberg HM, Larsen PR (eds) Williams textbook of endocrinology, 9th edn. Saunders, Philadephia, pp 249-340

38. Stoll B, Henry G, Reeds PJ, Yu H, Jahoor F, Burrin DG (1998) Catabolism dominates the first-pass intestinal metabolism of dietary essential amino acids in milk protein-fed piglets. J Nutr 128:606-614

39. Krebs M, Krssak M, Nowotny P et al. (2001) Free fatty acids inhibit the glucose-stimulated increase of intramuscular glucose-6-phosphate concentrations in man. J Clin Endocrinol Metab 86:2153-2160

40. De Fronzo RA, Ferranini E, Hendler R, Felig P, Wahren J (1983) Regulation of splanchnic and peripheral glucose uptake by insulin and hyperglycemia in man. Diabetes $32: 35-45$
41. Baron AD, Brechtel G, Wallace P, Edelman SV (1988) Rates and tissue sites of noninsulin- and insulin-mediated glucose uptake in humans. Am J Physiol 255:E769-E774

42. Cherrington AD (1999) Control of glucose uptake and release by the liver in vivo. Diabetes 48:1198-1214

43. Liljenquist JE, Mueller GL, Cherrington AD, Perry JM, Rabinowitz D (1979) Hyperglycemia per se (insulin and glucagon withdrawn) can inhibit hepatic glucose production in man. J Clin Endocrinol Metab 48:171-175

44. Ferranini E, De Fronzo RA, Gusenberg R et al. (1988) Splanchnic amino acid and glucose metabolism during amino acid infusion in dogs. Diabetes 237-245

45. Peters AL, Stumpf B, Hamm HH et al. (1976) Regulation of phosphoenolpyruvate carboxykinase by glutamine and ATP as possible control mechanisms of renal gluconeogenesis. Curr Probl Clin Biochem 6:336-345

46. Herzig S, Long F, Jhala US et al. (2001) CREB regulates hepatic gluconeogenesis through the coactivator PGC-1. Nature:179-183

47. Tappy L, Acheson K, Normand S et al. (1992) Effects of infused amino acids on glucose production and utilization in healthy human subjects. Am J Physiol 262:E826E833

48. Flakoll P, Wentzel L, Rice D, Hill J, Abumrad N (1992) Short-term regulation of insulin-mediated glucose utilization in four-day fasted human volunteers: role of amino acid availability. Diabetologia 35:357-366

49. Komjati M, Breitenecker F, Bratusch-Marrain P et al. (1985) Contribution of the glycogen pool and adenosine $3^{\prime}, 5^{\prime}$-monophosphate release to the evanescent effect of glucagon on hepatic glucose production in vitro. Endocrinology 116:978-986

50. Cherrington AD, Williams PE, Shulman GI, Lacy WW (1981) Differential time course of glucagon's effect on glycogenolysis and gluconeogenesis in conscious dogs. Diabetes 30:180-187

51. Rabinowitz D, Merimee TJ, Burgess JA, Riggs L (1966) Growth hormone and insulin release after arginine: indifference to hyperglycemia and epinephrine. J Clin Endocrinol Metab 26:1170-1172

52. Hanson RW, Reshef L (1997) Regulation of phosphoenolpyruvate carboxykinase (GTP) gene expression. Annu Rev Biochem 66:581-611

53. Abumrad NN, Williams P, Frexes-Steed M et al. (1989) Inter-organ metabolism of amino acids in vivo. Diabetes Metab Rev 5:213-226

54. Gannon M, Nuttall F (1987) Oral protein hydrolysate causes liver glycogen depletion in fasted rats pretreated with glucose. Diabetes 36:52-58

55. Wahren J, Felig P, Cerasi E, Luft R (1972) Splanchnic and peripheral glucose and amino acid metabolism in diabetes mellitus. J Clin Invest:1870-1878

56. Adibi SA, Mercer DW (1973) Protein digestion in human intestine as reflected in luminal, mucosal, and plasma amino acid concentration after meals. J Clin Invest 52:15861594

57. Rossetti L, Shulman GI, Zawalich WS (1987) Physiological role of cholecystokinin in meal-induced insulin secretion in conscious rats. Studies with L 364718, a specific inhibitor of CCK-receptor binding. Diabetes 36:12121215 